\title{
Optimization of Several Environmental Factors to Human Performance by Using Taguchi Method
}

\author{
A. R. Ismail ${ }^{\dagger}$ \\ Faculty of Mechanical Engineering, Universiti Malaysia Pahang, 22600 Pekan, Pahang, Malaysia \\ Tel: +6013- 3942463, E-mail: arasdan@gmail.com
}

M. H. M. Haniff

Department of Mechanical and Material Engineering, Faculty of Engineering and Built Environment, Universiti Kebangsaan Malaysia, 43600 UKM Bangi, Malaysia

M. Y. M. Yusof

Department of Mechanical and Material Engineering, Faculty of Engineering and Built Environment, Universiti Kebangsaan Malaysia, 43600 UKM Bangi, Malaysia

M. N. A. Rahman

Department of Mechanical and Material Engineering, Faculty of Engineering and Built Environment, Universiti Kebangsaan Malaysia, 43600 UKM Bangi, Malaysia

\section{J. A. Ghani}

Department of Manufacturing and Material Engineering, Faculty of Engineering and Built Environment Universiti Kebangsaan Malaysia, 43600 UKM Bangi, Malaysia

Received, January 7, 2009; Revised, March 16, 2010; Accepted, April 15, 2010

\begin{abstract}
The objective of this study is to determine the dominance effects of environmental factors such as Illuminance, humidity and Wet Bulb Globe Temperature (WBGT) on the operators' productivity at Malaysian electronic industry. A case study was carried out at an electronic components assembly factory. The environmental factors examined were the Illuminance (lux), humidity and WBGT of the surrounding workstation area. Two sets of representative data including the illuminance, humidity and WBGT level and production rate were collected during the study. The production rate data were collected through observations and survey questionnaires while the illuminance level was measured using photometer model RS 180-7133, the humidity and WBGT level were measured by using Quest Temp apparatus and humidity. Taguchi Method was utilized to find the sequence of dominant factors that contributed to the productivity of operator at that specified production workstation. The study reveals that the dominant factor contributed to the productivity was WBGT, followed by illuminance and humidity.
\end{abstract}

Keywords: Poductivity, Iluminance, Hmidity, Wet Bulb Globe Temperature(WBGT), Dminant

\section{INTRODUCTION}

Robust design is an engineering methodology for obtaining product and process conditions, which are minimally sensitive to the various causes of variation to produce high-quality products with low development and manufacturing costs (Park, 1996). Taguchi's parameter design is an important tool for robust design. It offers a simple and systematic approach to optimize design for performance, quality and cost. Two major tools used in robust design are (Park, 1996; Unal and Dean, 1991; Phadke, 1989):

- Signal to noise ratio, which measures quality with emphasis on variation, and

- Orthogonal arrays, which accommodate many de-sign factors simultaneously.

Taguchi's approach is totally based on statistical design of experiments (Park, 1996), and this can economically satisfy the needs of problem solving and prod-

$\uparrow$ : Corresponding Author 
uct or process design optimization (http://www.vkroy.com/ doe.html). By applying this technique one can significantly reduce the time required for experimental investigation, as it is effective in investigating the effects of multiple factors on performance as well as to study the influence of individual factors to determine which factor has more influence, which less (Park, 1996; http://www. kroy.com/up-doe.html). Some of the previous works that used the Taguchi method as tool for design of experiment in various areas including metal cutting are listed in the references (Yang and Tarng, 1998; Lin, 2002; Tsui, 1999; Zhang and Wang, 1998; Si and Tong, 1997; Kopac et al., 2002).

The most important stage in the design of an experiment lies in the selection of control factors. As many factors as possible should be included, so that it would be possible to identify non-significant variables at the earliest opportunity. Taguchi creates a standard orthogonal array to accommodate this requirement. Depending on the number of factors, interactions and levels needed, the choice is left to the user to select either the standard or column-merging method or idle-column method, or etc. Two of the applications in which the concept of $\mathrm{S} / \mathrm{N}$ ratio is useful are the improvement of quality through variability reduction and the improvement of measurement. The $\mathrm{S} / \mathrm{N}$ ratio characteristics can be divided into three categories when the characteristic is continuous (Park, 1996):

Nominal is the best characteristic;

$$
\mathrm{S} / \mathrm{N}=10 \log \frac{\bar{y}}{s_{y}^{2}}
$$

Smaller the better characteristics;

$$
\mathrm{S} / \mathrm{N}=10 \log \frac{1}{n}\left(\sum y^{2}\right)
$$

Larger the better characteristics;

$$
\mathrm{S} / \mathrm{N}=-10 \log \frac{1}{n}\left(\sum \frac{1}{y^{2}}\right)
$$

Where, $\bar{y}$ is the average of observed data, $s_{y}^{2}$ is variance of $y, n$ is number of observations, and $y$ is the observed data. For each type of the characteristics, with the above $\mathrm{S} / \mathrm{N}$ ratio transformation, the higher the $\mathrm{S} / \mathrm{N}$ ratio the better is the result.

Improving workers' productivity, occupational health and safety are major concerns of industry, especially in developing countries. However, these industries are featured with improper workplace design, ill-structured jobs, mismatch between workers' abilities and job demands, adverse environment, poor human-machine system design and inappropriate management programs (Shikdar and Sawadeq, 2003). Light, noise, air quality and the thermal environment were considered factors that would influence the acceptability and performance on the occupants of premises (Olesen, 1995). Dua (1994) stated that lower emotional health is manifested as psychological distress, depression and anxiety, whereas lower physical health is manifested as heart disease, insomnia, headaches, and infections. These health problems could lead to organizational symptoms such as job dissatisfaction, absentteeism, and poor work quality. Irritated, sore eyes and throat, hoarseness, stuffy congested nose, excessive mental fatigue, headache and unusual tiredness were all signs of the negative work-place environmental conditions (Tarcan et al., 2004).

Previous research done by Ettner and Grzywacz (2001) showed that the work environments were associated with perceived effects of work on health. This research used a national sample of 2,048 workers who were asked to rate the impact of their respective jobs job on their physical and mental health. Regression analyses proved that the workers' responses were significantly correlated with health outcomes. In addition to this, Shikdar and Sawaqed (2003) pointed out that there was high correlation between performance indicators and health, facilities, and environmental attributes. In other words, companies with higher health, facilities, and environmental problems could face more performance related problems such as low productivity, and high absenteeism. Employees with complaints of discomfort and dissatisfaction at work could have their productivity affected, result of their inability to perform their work properly (Leaman, 1995).

A study of office workers at the call centre by Boyce (2004) indicated that illuminace have a statistically significant effect on average handling time that is greater than $1 \%$. The biggest effect of these variables predicted by the regression is between $17 \%$ to $19 \%$ reduction in average handling time. Staffan and Knez (2001) had investigated on how noise, air temperature, and illuminance combine or interact in their effects on cognitive performance. The results from Staffan and Knez study showed that they worked faster in noise but at the cost of lesser accuracy. Interactions were found between noise and heat on the long-term recall of a text, and between noise and light on the free recall of emotionally toned words. In metal industry, Bommel et al. (2002) conducted a study on the effect of increasing the illuminance based on increased task performance, reduction of rejects and the decreased number of accidents. The result of the study revealed that the increasing of illuminance from the minimum required of 300 lux (minimum) to 500 lux could lead to an increase of productivity from $3 \%$ to $11 \%$ based on realistic assumptions that the increase of illuminance from 300 lux to 2000 lux would increase the productivity from $15 \%$ to $20 \%$ (Bommel et al., 2002). Juslen and Tenner (2005) described the mechanisms involved in enhancing human performance by changing the lighting in the industrial workplace through visual performance, visual comfort, visual ambience, interpersonal relationships, biological clock, stimulation, job satisfaction, problem solving, the halo effect, and the change process.

According to the Fisk et al. (1997) productivity was one of the most important factors affecting the overall 
performance to any organization, from small enterprises to entire nations. Increased attention had focused on the the work environment and productivity since the 1990s. Laboratory and field studies showed that the physical and chemical factors in the work environment could have a notable impact on the health and performance of the occupants, and consequently on the productivity. Workplace environmental conditions, such as humidity, indoor air quality, and acoustics have significant relationships with workers' satisfaction and performance (Tarcan et al., 2004; Marshall et al., 2002; Fisk, 2000). Indoors air quality could have a direct impact on health problems and leads to uncomfortable workplace environments (Juslen and Tenner, 2005; Fisk and Rosenfeld, 1997; Marshall et al., 2002).

\section{METHODOLOGY}

\subsection{Selection of Location and Subjects}

The study was conducted in a production line at a Japanese company manufacturing electronics products. In this study the authors were investigating the effects of environmental factors towards productivity. The main objectives were to obtain the relationship of the illuminance (lux), relative humidity (\%) and Wet Bulb Globe Temperature on the operators' productivity based on output of assemblies. The production line was selected based on a descriptive study by distributing a survey questionaire. The analysis from the survey showed that $80 \%$ of the production operators strongly agreed that the environmental factors especially lighting, humidity and temperature had greatly influenced on their work productivity.

In addition the production line was selected by the management of the plant due to its problems and low productivity volume. The sample comprise of 11 female operators, age between 20 30 years old mostly Malaysians of non-degree holders and had been working with the organization for less than 5 years. Majority of the respondents reported that they work for more than 49 hours per week. Their task is to assemble electronics parts on the circuit board for the television system tuner. Figure 1 shows the flow chart of work sequences in the production line. The standard production rate determined by the previous feasibility study for assembling a complete television tuner is 250 units per hour of production time. In Figure 1, the workers deal with the microscale materials. They use the microscope to observe the defects on products. So they do really needs the significant level of lighting to have good visual condition in order to detect any defects. Observed that, poor condition of temperature and humidity can bring an effects either over sweating rate or dryness to the workers skin. If the workers feel over sweating or dryness, they cannot performed well on their task.

\subsection{Data Gathering}

The variables in this study are production rate, illuminance, relative humidity (\%) and Wet Bulb Globe Temperature. The measurements for illuminance level was performed using photometer model RS 180-7133. The operators' performance level was represented by the production rate. The amount of the products assembled were recorded for every 30 minutes. The data gathered was compared to the levels of illuminance (lux), relative humidity (\%) and Wet Bulb Globe Temperature. The instrument is capable of calculating computed the value of WBGT automatically.

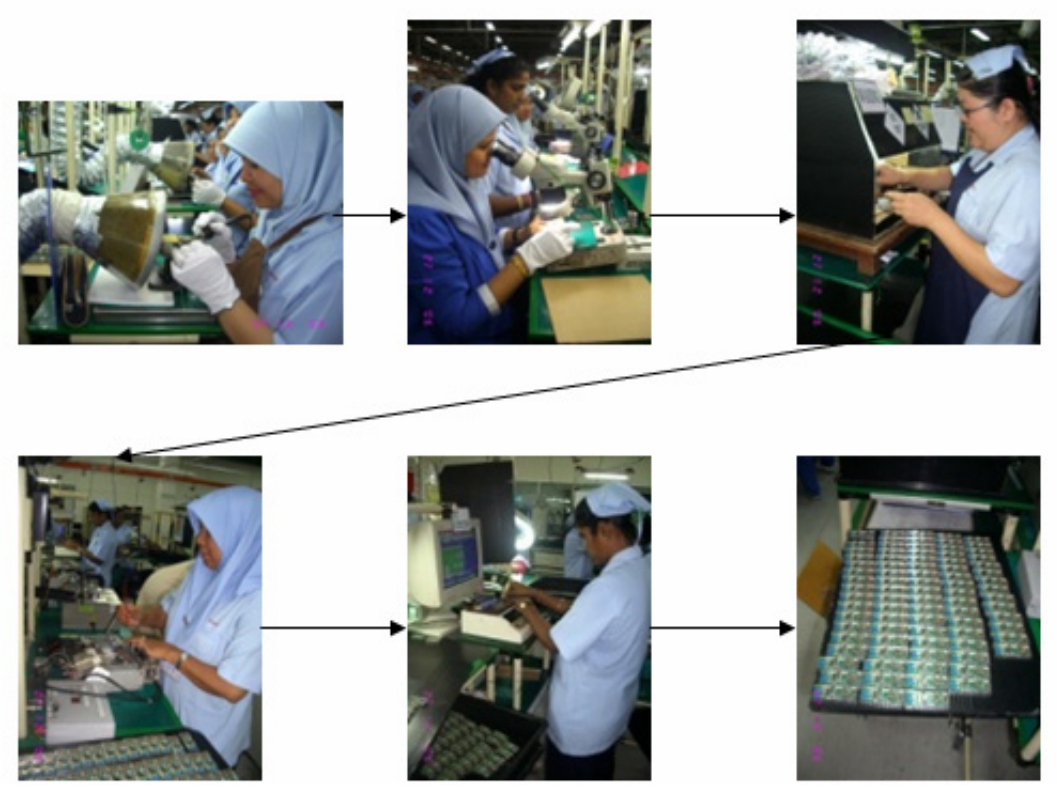

Figure 1. The works sequence to assemble complete TV tuner. 


\subsection{Analysis Method}

The Taguchi design of experiment was employed in this experiment with two factors at two levels each. The fractional factorial designs used was a standard $\mathrm{L}_{8}$ orthogonal array (Park, 1996). This orthogonal array was chosen because of its minimum number of experimental trials. Each row of the matrix represented one trial. However, the sequence in which those trials were carried out was random. The factors and levels identified in this study were shows in Table 1. Table 1 shows the factors and levels used in the experiment. For the illuminance factor, the range of illuminance level was chosen whether below 500 lux for for discomfort level and more than 500 lux for comfort level (Bommel et al., 2002; Juslen and Tenner, 2005). A relative humidity factor consists of two level which is below $60 \%$ for the comfort level and more than $60 \%$ for discomfort level (Tsutsumi et al., 2007). Lastly for Wet-bulb globe temperature, it consists of two levels which is below than $23^{\circ} \mathrm{C}$ for comfort level and more than $23^{\circ} \mathrm{C}$ for discomfort level (Niemela et al., 2002).

\section{RESULTS AND DISCUSSION}

Table 2 shows the data of production rate, illuminance level and time taken for every 30 minutes. A graph was plotted to show the relationship between production rate and illuminance level. Figure 3 shows the graph describing the relationship between production rate versus illuminance level. The objective of the experiment is to obtain the optimum level of environmental parameters

Table 1. Factors and levels used in the experiment.

\begin{tabular}{|l|c|c|}
\hline \multirow{2}{*}{\multicolumn{1}{|c|}{ Factors }} & \multicolumn{2}{c|}{ Level } \\
\cline { 2 - 3 } & 0 & 1 \\
\hline \hline A-WBGT & $<23$ & $>23$ \\
\hline B-Illuminance (Lux) & $<500$ & $>500$ \\
\hline C-Humiduty (\%) & $<60$ & $>60$ \\
\hline
\end{tabular}

(WBGT, illuminance and humidity) in order to obtain the better results for production rate (high value) and therefore the optimum characteristic of environmental effects should be quantified.

\subsection{Linear Relation Analysis}

Based on the graph in Figure 2, the production rate were improved with the increase of the illuminance (lux). The results obtained for the illuminance is in-line with the finding from Bommel et al. (2002) and Juslen and Tenner (2005) where the increasing of illuminance levels lead to an increase in productivity. The same trend is observed for the relative humidity (\%) and the productivity as shown in Figure 3.

The finding on the effect of relative humidity towards productivity is contradicted with the finding by Tsutsumi et al. (2007) where they had found the subjective performance was at the same level under four different levels of relative humidity. However, Tsutsumi et al. (2007) reported their subjects were more tired at $70 \% \mathrm{RH}$ after relative humidity (\%) step change.

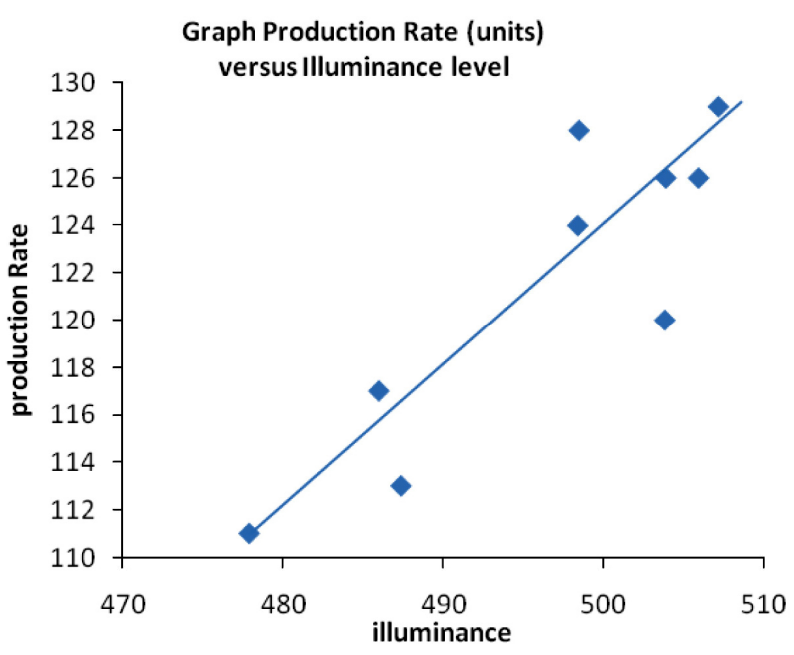

Figure 2. Production Rate versus Illuminance level.

Table 2. Data on the Illuminance level, Relative Humidity, Wet Bulb Globe Temperature and Production Rate.

\begin{tabular}{|c|c|c|c|c|c|}
\hline $\begin{array}{c}\text { Time } \\
(\mathrm{Hrs})\end{array}$ & $\begin{array}{c}\text { Production } \\
\text { Target } \\
\text { (Units) }\end{array}$ & $\begin{array}{c}\text { Production } \\
\text { Rate } \\
\text { (Units) }\end{array}$ & $\begin{array}{c}\text { Illuminance } \\
\text { (Lux) }\end{array}$ & $\begin{array}{c}\text { Humidity } \\
(\%)\end{array}$ & WBGT \\
\hline \hline $8.25 \sim 8.55$ & 125 & 124 & 498.35 & 61.01 & 23.01 \\
\hline $8.55 \sim 9.25$ & 125 & 128 & 498.43 & 59.93 & 23.10 \\
\hline $9.25 \sim 9.55$ & 125 & 126 & 505.87 & 59.30 & 23.09 \\
\hline $10.55 \sim 11.25$ & 125 & 120 & 503.77 & 58.87 & 23.12 \\
\hline $11.25 \sim 11.55$ & 125 & 126 & 503.83 & 59.30 & 23.05 \\
\hline $11.55 \sim 12.25$ & 125 & 129 & 507.10 & 59.05 & 22.86 \\
\hline $13.40 \sim 14.10$ & 125 & 113 & 487.35 & 55.48 & 23.25 \\
\hline $14.10 \sim 14.40$ & 125 & 117 & 485.97 & 55.26 & 23.19 \\
\hline $14.40 \sim 15.10$ & 125 & 111 & 477.90 & 55.37 & 23.32 \\
\hline
\end{tabular}




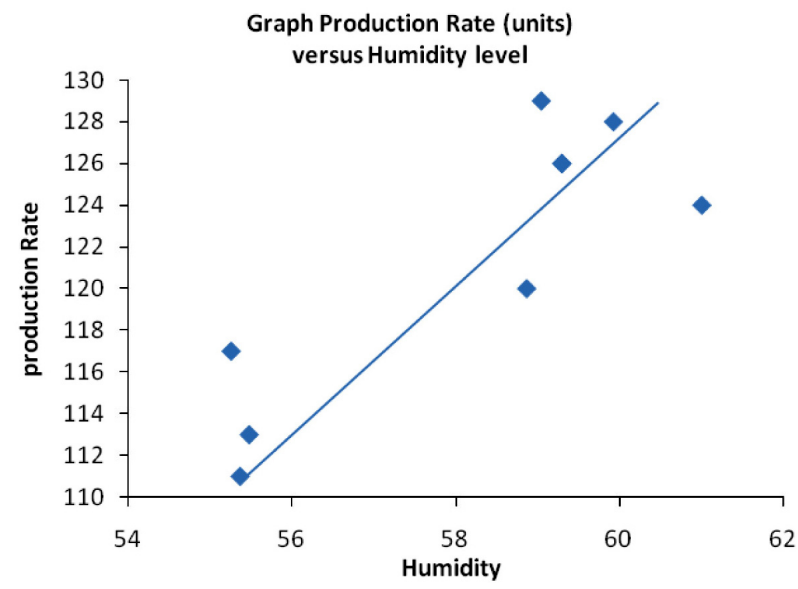

Figure 3. Production Rate versus Relative humidity level $(\%)$.

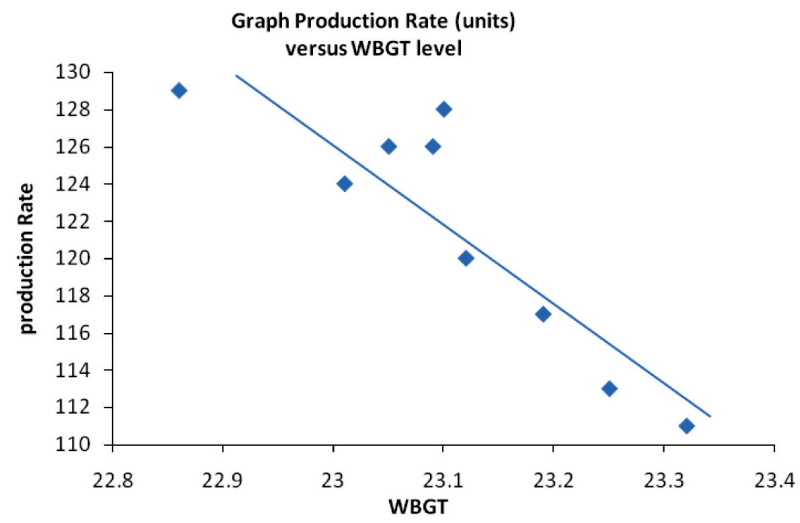

Figure 4. Production Rate versus Wet Bulb Globe Temperature level.

The trend obtained for illuminance and relative humidity towards productivity is different compared to the relation of Wet Bulb Globe Temperature (WBGT) and productivity. Figure 4 shows by increasing the Wet Bulb Globe Temperature will reduce the performance and productivity of the operators. The findings for Wet Bulb Globe Temperature were similar to finding of Fisk and Rosenfeld (1997) where by increasing the air ventilation will significantly increase the performance of the operators. The productivity increase cause by the WBGT could be related to the attention and cognitive aspect of the operators, which has been studied by Staffan and Knez (2001). They found that the combination of air temperature and illuminance level had a significant effect on cognitive performance.

\subsection{Taguchi Approach}

Taguchi recommends analyzing the means and SN ratio using conceptual approach that involves graphing the effects and visually identifying the factors that appear to be significant, without using ANOVA, thus making the analysis simple (Park, 1996). The bigger the better charac-

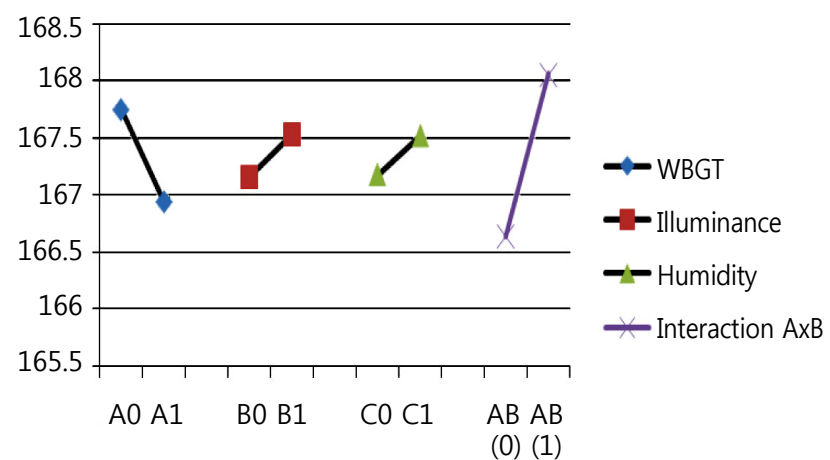

Figure 5. The bigger the better characteristic SN ratio graph for 3 environmental factors.

teristic $\mathrm{SN}$ ratio graph for the production rate is shown in Figure 5. It shows that the interaction AxB (WBGT and illuminance) is the most significant factor in controlling the production rate, followed by the WBGT, illuminance and humidity. Figure 5 also shows the optimum condition for the production rate is at level 0 of WBGT (less than $23^{\circ} \mathrm{C}$ ), level 1 (more than $500 \mathrm{Lux}$ ) of illuminance and level 1 (more than $60 \%$ ) of humidity. The result from $\mathrm{L}_{8}$ orthogonal array and computed $\mathrm{SN}$ ratio for environment parameters and productivity were show in Table 3.

\subsection{Pareto ANOVA Analysis}

One of the methods to analyze the data for process optimization is the use of Pareto ANOVA (Park, 1996). The Pareto ANOVA is a simplified ANOVA method, which uses the Pareto principles. It is a quick and easy method to analyze results of the parameter design. It does not require an ANOVA table and therefore does not use F-tests. The Pareto ANOVA technique of analysis requires the least knowledge about the ANOVA method and suitable for both engineers and industrial practitioner. Pareto ANOVA analysis performed in Table 4 shows that the interaction between WBGT and illuminance effect contribute more than $68 \%$ on the production rate followed by WBGT, illuminance and humidity of about $4.9 \%$ and $3.98 \%$ respectively. The humidity effect is insignificant in controlling the production rate in this study. From the two-way table performed in Table 5, the optimum levels for factor A and B are A0B1, since the analysis gives the largest value of 42.21 .

From the literature, only a few studies have been conducted in the area to establish a dominant environmental parameter contributed to the worker productivity. The authors believe the study had achieved the objective in order to establish the dominant environmental parameters contributed to the productivity. The finding from the current investigation corresponds to the result of study by Bommel et al. (2002) where the illuminance play a role in determining the comfort level among the worker in assembly production line. The two dominant factors obtain in this study will provide a guideline to assist engineers to determine the illuminance level and 
Table 3. Result for L8 orthogonal array for production rate and the computed SN ratio.

\begin{tabular}{|c|c|c|c|c|c|c|c|c|c|}
\hline \multirow{2}{*}{$\begin{array}{l}\text { Experiment } \\
\text { number }\end{array}$} & \multicolumn{7}{|c|}{ Column number } & \multirow{2}{*}{$\begin{array}{c}\text { Prod } \\
\text { rate }\end{array}$} & \multirow{2}{*}{$\begin{array}{c}\text { SN Ratio (the } \\
\text { bigger the better }\end{array}$} \\
\hline & 1 & 2 & 3 & 4 & 5 & 6 & 7 & & \\
\hline 1 & 0 & 0 & 0 & 0 & 0 & 129 & 117 & 117 & 41.63 \\
\hline 2 & 0 & 0 & 0 & 1 & 1 & 129 & 117 & 124 & 41.80 \\
\hline 3 & 0 & 1 & 1 & 0 & 0 & 129 & 129 & 129 & 42.21 \\
\hline 4 & 0 & 1 & 1 & 1 & 1 & 129 & 126 & 128 & 42.12 \\
\hline 5 & 1 & 0 & 1 & 0 & 1 & 128 & 117 & 128 & 41.87 \\
\hline 6 & 1 & 0 & 1 & 1 & 0 & 128 & 117 & 128 & 41.87 \\
\hline 7 & 1 & 1 & 0 & 0 & 1 & 126 & 120 & 111 & 41.48 \\
\hline 8 & 1 & 1 & 0 & 1 & 0 & 117 & 126 & 124 & 41.74 \\
\hline Basic mark & $\mathrm{A}$ & $\mathrm{B}$ & $\mathrm{AB}$ & $\mathrm{C}$ & $\mathrm{AC}$ & $\mathrm{BC}$ & $\mathrm{ABC}$ & & \\
\hline Assignment & & & & & & & & & \\
\hline
\end{tabular}

Table 4. Pareto ANOVA analyses for production rate.

\begin{tabular}{|c|c|c|c|c|c|}
\hline \multicolumn{2}{|c|}{ Factor and Interaction } & A & B & $\mathrm{C}$ & $\mathrm{AB}$ \\
\hline \multirow{2}{*}{ Sum at factor } & 0 & 167.76 & 167.17 & 167.18 & 166.64 \\
\hline & 1 & 166.95 & 167.55 & 167.53 & 168.07 \\
\hline \multicolumn{2}{|c|}{ Sum of Squares of diff (S) } & 0.66 & 0.14 & 0.12 & 2.03 \\
\hline \multicolumn{2}{|c|}{ Contribution ratio (\%) } & 22.30 & 4.88 & 3.98 & 68.84 \\
\hline \multicolumn{6}{|c|}{ Pareto Diagram } \\
\hline \multicolumn{2}{|c|}{ Factor and Interaction } & $\mathrm{AB}$ & A & B & $\mathrm{C}$ \\
\hline \multicolumn{2}{|c|}{ Cumulative contribution } & 68.84 & 22.3 & 4.88 & 3.98 \\
\hline \multicolumn{2}{|c|}{ Check on significant interaction } & \multicolumn{4}{|c|}{ AB Two-way table in Table 5} \\
\hline \multicolumn{2}{|c|}{ Remarks: } & \multicolumn{4}{|c|}{$\begin{array}{l}\text { The significant factors and interactions are chosen from the left hand side in } \\
\text { the above Pareto diagram which cumulatively contributes about } 90 \% \text {. }\end{array}$} \\
\hline \multicolumn{2}{|c|}{$\begin{array}{c}\text { combination of significant factor } \\
\text { level }\end{array}$} & \multicolumn{4}{|c|}{ A0B1C1 (optimum level for factors A and B are obtained from Table 5) } \\
\hline
\end{tabular}

Table 5. AB Two-way table for average $\mathrm{S} / \mathrm{N}$ ratio for production rate factors and significant interaction.

\begin{tabular}{|c|c|c|c|}
\hline & A0 & A1 & Total \\
\hline \hline B0 & 41.8 & 41.87 & 83.67 \\
\hline B1 & 42.21 & 41.48 & 83.69 \\
\hline Total & 84.01 & 83.35 & 167.37 \\
\hline
\end{tabular}

WBGT during the feasibilities study to allow assembly production line achieves the optimum output.

The finding also will be useful to engineers in design lighting systems in order to minimize the use of power and control the productivity of workers. The dominant environmental parameter obtain in this study is only ap- 
plicable to present the current condition for the selected area of assembly workstation at Malaysian electronics industries. From the results of the study also concluded that there is relationship between illuminance, humidity and WBGT level with production rate. An analysis of the result for production rate using both conceptual $\mathrm{SN}$ ratio and Pareto ANOVA approach reveals a similar conclusion.

i: The optimum condition for production rate are at level 0 of WBGT (less than $23^{\circ} \mathrm{C}$ ), level 1 (more than 500 lux) of illuminance. These factors contribute $68 \%, 22 \%$, and $4.8 \%$ respectively. Humidity is found insignificant in affecting the production rate.

ii: In all cases studied the two most significant factors in controlling the production rate is the interaction between WBGT and illuminance.

Therefore the findings from this study are in line with the previous study that indicated WBGT and illuminance play an important role in controlling the production rate because the both factors will contributed to the comfort level of worker (Shikdar and Sawadeq, 2003; Olesen, 1995; Dua, 1994).

\section{CONCLUSION}

Past research on the modeling relationship of workplace environmental factors to the productivity or performance is very limited. In addition they are characterized by a short time perspective, not enough engineering data regarding the lead time, expected output capacity or perception with emphasis on survey methods, statistical analysis, satisfaction and the preferences measurement. This study was done to prove empirically the previous perception studies, which based on the role of environmental factors to productivity. It is hoped that this study would be beneficial to the electronic manufacturing industries in Malaysia.

The research findings are restricted to the Malaysian workplace environment, where the awareness among workers on improving productivity is still low. The results might vary for tests carried out for different sample sizes, types of industries and countries. The study could be more extensive if the fraction of defect rate for the product is included in the analysis. Nevertheless the authors believed the modeling of production rate, as a time series data is more than adequate to understand the affect of environmental factors towards productivity.

\section{ACKNOWLEDGEMENT}

The authors wish to thank the management of Hitachi Electronics (M) Limited for their willingness to take part in this study.

\section{REFERENCES}

Bommel, W. J. M., Van Den Beld, G. J., and Van Ooyen,
M. H. F. (2002), Industrial Lighting And Productivity. Technical Report From Philips, The Netherlands, August.

Boyce, P. (2004), Window and Office: A Study of Office Worker Performance and the Indoor Environment, Technical Report, Lighting Research Centre, Rensselaer Polytechnic Institute.

Dua, J. K. (1994), Job Stressors and Their Effects on Physical Health, Emotional Health, and Job Satisfaction in a University, Journal of Educational Administration, 32(1), 59-78.

Ettner, S. L. and Grzywacz, J. G. (2001), Workers’ perceptions of how jobs affect health: a social ecological perspective, Journal of Occupational Health Psychology, 6(2), 101-131.

Fisk W. J. and Rosenfeld A. H. (1997), Estimates of improved productivity and health from better indoor environments. Indoor Air, 7, 158-172.

Fisk, W. J. (2000), Health and Productivity Gains From Better Indoor Environments and Their Relationship with Building Energy Efficiency. Annual Review of Energy and The Environment, 25(2), 537-566.

Juslen, H. and Tenner, A. (2005), Mechanisms Involved In Enhancing Human Performance By Changing The Lighting In The Industrial Workplace, International Journal of Ergonomic, 35(9), 843-855.

Kopac, J., Bahor, M. and Sokovic, M. (2002), Optimal Machining Parameters for Achieving the Desired Surface Roughness in Fine Turning of Cold pre-Formed Steel Workpieces, In Press (internet), International Journal of Machine Tool And Manufacture.

Leaman, A. (1995), Dissatisfaction and office productivity, Facilities, 13(2), 13-19.

Lin, T. R. (2002), Experimental Design and Performance Analysis of TiN-Coated Carbide Tool in Face Milling Stainless Steel, In Press, Journal of Material Processing Technology, 56(54), 1-7.

Marshall, L., Erica, W., Alan, A. and Sanborn, M. D. (2002), Identifying and Managing Adverse Environmental Health Effects: 1. Taking an Exposure History, Canadian Medical Association Journal, 166(8), 1049-1055.

Niemela, R., Hannula, M., Rautio, S., Reijula, K. and Railio, J. (2002), The effect of air temperature on labour productivity in call centres- a case study, Energy and Buildings, 34, 759-764.

Olesen, B. W. (1995), International standards and the ergonomics of the thermal environment, Journal of Applied Ergonomics, 26, 293-302.

Park, S. H. (1996), Robust Design and Analysis for Quality Engineering, Chapman and Hall.

Phadke, M. S. (1989), Quality Engineering Using Robust Design, Prentice Hall, New Jersey.

Roy, V. K. Nutek, Inc, http://www.vkroy.com/up-doe.html Shikdar, A. A. and Sawaqed, N. M. (2003), Worker 
productivity, and occupational health and safety issues in selected industries, Computers and Industrial Engineering, 45(4), 563-572.

Si, C. T. and Tong, L. I. (1997), Multi Response Robust Design by Principal Component Analysis, Total Quality Management, 8(6), 409-416.

Staffan, H. and Knez, I. (2001), Effect of Noise, Heat, And Indoor Lighting On Cognitive Performance And Self-Reported Affect, Journal of Environment Psychology, 21(3), 291-299.

Tarcan, E., Varol, E. S., and Ates, M. A. (2004), Qualitative Study of Facilities and Their Environ-mental Performance Management of Environmental Quality: An International Journal, 15(2), 154-173.

Tsui, K. L. (1999), Modeling and Analysis of Dynamic Robust Design Experiments, IEE Transactions, 31, 113-1122.
Tsutsumi, H., Tanabe, S., Harigaya, J., Iguchi, Y. and Nakamura, G. (2007), Effect of Humidity On Human Comfort And Productivity After Step Changes From Warm And Humid Environment, Journal of Building and Environment, Building and Environment, 42(12), 4034-4042.

Unal, R. and Dean, E. B. (1991), Taguchi approach to Design optimization for Quality and Cost: an Overview, Proceeding of the International Society of $\mathrm{Pa}$ rametric Analyst 13 th Annual May, 21-24.

Yang, W. H. and Tarng, Y. S. (1998), Design Optimization of Cutting Parameters for Turning Operations Based on the Taguchi Method, Journal of Material Processing Technology, 84, 122-129.

Zhang, C. and Wang, H. P. (1998), Robust Design of Assembly and Machining Tolerance Allocations, IEE Transactions, 30, 17-29. 